\section{Experimental use of alcohol in early adolescence: the 11-year follow-up of the 1993 Pelotas (Brazil) birth cohort study}

\author{
Uso experimental de álcool no início da adolescência: \\ a visita de 11 anos da coorte de nascimentos de \\ Pelotas, Rio Grande do Sul, Brasil, 1993
}

\author{
1 Programa de Pós-graduação \\ em Epidemiologia, \\ Universidade Federal de \\ Pelotas, Pelotas, Brasil. \\ 2 Escola de Saúde, \\ Universidade Católica de \\ Pelotas, Pelotas, Brasil. \\ ${ }^{3}$ Faculdade de Nutrição, \\ Universidade Federal de \\ Pelotas, Pelotas, Brasil. \\ 4 Programa de Pós-graduação \\ em Educação Física, \\ Universidade Federal de \\ Pelotas, Pelotas, Brasil. \\ Correspondence \\ R. B. Noal \\ Programa de Pós-graduação \\ em Epidemiologia, \\ Universidade Federal de \\ Pelotas. \\ Rua Marechal Deodoro \\ 1160, Pelotas, RS 96020-220, \\ Brasil. \\ ricardonoal@yahoo.com.br
}

\begin{abstract}
The aim of this study was to estimate the prevalence of experimental alcohol intake and associated factors in early adolescence. The overall sample consisted of 4,452 adolescents (mean age = 11.3 years; $S D=0.3$ ) from the 1993 birth cohort in Pelotas, Rio Grande do Sul State, Brazil. Experimental use of alcohol was reported by $17.5 \%$ of the interviewees (95\%CI: 16.3-18.6), and 5\% reported having tried alcohol at nine years of age or younger. Prevalence of experimental alcohol use was higher among adolescents whose mothers had consumed alcohol during pregnancy, whose parents consumed alcohol, who worked outside the home themselves, and who had ever tried smoking. Family strife, parental alcohol intake, and adolescent smoking were strong predictors of experimental alcohol use in early adolescence. Special attention should be targeted to these groups in order to avoid heavy and premature alcohol use in early adolescence.
\end{abstract}

Alcoholic Beverages; Adolescent; Cohort Studies
Ricardo B. Noal 1,2

Ana M. B. Menezes 1

Cora Luiza Araújo 1,3

Pedro C. Hallal 1,4

\section{Introduction}

According to the World Health Organization (WHO), psychoactive drugs are substances that act on the central nervous system, producing behavioral, mood, and cognitive alterations 1,2. Alcohol is classified as a depressant type of psychoactive substance, causing initial euphoria and subsequent somnolence and reduced reflexes. Despite alcohol's potential for developing addiction, it is one of the few drugs whose consumption is not only allowed, but routinely encouraged through industry advertising.

The burden of disease attributed to alcohol consumption is extremely high ${ }^{3}$. Alcohol abuse is considered a public health problem due to its social, economic, and health consequences ${ }^{4}$. Alcohol consumption is related causally to some 60 diseases in the International Classification of Diseases 5. In the United States, alcohol is the fourth cause of death in individuals 10-24 years of age. Importantly, earlier initiation to alcohol consumption is associated with increased risk of acute complications like injuries, motor vehicle accidents, and unprotected sex 6 . Reduction of the risk attributed to alcohol-related diseases is a WHO priority 4 .

In Brazil, alcohol is the most widely consumed drug in all age groups, and its intake has increased especially in young people (12-15 years of age) 7 . Experimental use of alcohol begins in childhood and is consolidated in adolescence ${ }^{8}$. Fergusson 
et al. 8, after controlling for various confounders, observed that children who first tried alcohol before six years of age, as compared to children who never tried alcohol before 13 years, showed 1.9 to 2.4 times the risk of frequent alcohol use at 15 years. Galduróz \& Carlini ${ }^{9}$, in a study in 107 large Brazilian cities (more than 200,000 inhabitants each), observed that approximately half (48.8\%) of adolescents 12-17 years of age had already tried alcohol, and that $5.2 \%$ were worried about their own consumption pattern.

Considering the high prevalence of alcohol use by adolescents and its potential acute and chronic harmful effects on individual health, the aim of this study was to assess the prevalence of experimental alcohol use among adolescents from the 1993 birth cohort in Pelotas, Rio Grande do Sul State, Brazil. The study further investigated the association between the experimental use of alcoholic beverages and socio-demographic factors, family relations, scholastic performance, and experimental use of other drugs.

\section{Methods}

All hospital births in the city of Pelotas in 1993 were monitored. The mothers answered a questionnaire, and the newborns were weighed and measured. Sub-samples of these individuals were visited at 1,3 , and 6 months and 1, 4, 6, and 9 years of age. In 2004-2005, all the cohort members were searched for a new follow-up, the methodological details of which have been described elsewhere 10 .

Using an anonymous, confidential, self-applied questionnaire, the study collected data on the experimental use of alcohol, cigarettes, and other drugs, in addition to adolescents' perception of their family relations.

The following question was used to measure the dependent variable, i.e., experimental use of alcoholic beverages: "Have you ever tried alcohol?". The outcome was further described with questions on age at initiation ("How old were you the first time you tried alcohol?"), frequency ("In the last 30 days, how many days did you drink alcoholic beverages?"), and alcohol abuse ("Have you ever gotten smashed or really drunk?”).

Demographic characteristics (gender and self-reported skin color) and a socioeconomic index (household assets index in quintiles) were used as independent variables. Maternal alcohol intake during pregnancy (yes/no) and current parental alcohol intake (neither, one, or both parents) were also used.

The adolescents were asked to compare their own family to others they knew, and to say whether their own family fought or argued a little or a lot. Scholastic performance was assessed by grade repetition, categorized as: never repeated a grade, repeated once, and repeated more than once. Running away from home was assessed with the question: "Have you ever run away from home?" The adolescents were also asked if they worked outside the home.

Experimental use of cigarettes was defined with the question "Have you ever tried smoking cigarettes, even just one or two puffs?”. Experimental use of illicit drugs was based on the following questions: "Have you ever tried: (a) marijuana (yes/no), (b) glue (yes/no), or (c) solvent or thinner (yes/no)?". A dichotomous categorical variable was created, considering a history of at least one of the above-mentioned substances.

Statistical analysis used Stata 9.2 (Stata Corp., College Station, USA). The analysis began with a description of the sample, followed by crude analysis of the dependent variables and their association with theindependent variables, through the chi-square for heterogeneity and linear trend tests. A hierarchical model was used to calculate the crude and adjusted prevalence ratios at two levels 11 . This model proposes a chain of possible causal determinants, beginning at the most distal level with the demographic variables and the socioeconomic variable and ranging to the most proximal level with the parental alcohol-related variables, family relations, and use of cigarettes and other drugs by the adolescent. Poisson regression was performed for each level of analysis 12 due to the high prevalence of the outcome, using the Wald test for heterogeneity and the linear trend test. The significance level for associations between the independent and dependent variables was set at $5 \%$. Using backwards elimination, the study maintained the variables with $\mathrm{p} \leq$ 0.20 for controlling confounders.

\section{Results}

Data were obtained for 4,452 adolescents, representing $87.5 \%$ of the original cohort ${ }^{13}$. As for unknown data, all the variables except for parental alcohol use $(26.3 \%)$ had a maximum of $7.6 \%$ of unknown or missing values.

Alcohol consumption during pregnancy was reported by $5 \%$ of the mothers. As for parental alcohol use, 39\% reported that both parents consumed alcohol and $27 \%$ that neither parent used alcoholic beverages. Approximately $6 \%$ of the adolescents felt that their own families fought or argued more than others, and slightly more than $3 \%$ reported having run away from home. Thirtyfive percent of the adolescents had repeated one 
grade in school and $14 \%$ more than one grade. Working outside the home was reported by 193 of the adolescents (4.4\%). Some $3.7 \%$ of the interviewees had tried smoking cigarettes, and $0.4 \%$ reported having tried some type of illicit drug.

Experimental use of alcohol was reported by 757 adolescents, or $17.5 \%$ of those interviewed (95\%CI: 16.3-18.6) (Figure 1). Five percent reported having tried alcoholic beverages at nine years or younger. Some $5 \%$ of those who reported having tried alcohol also reported having gotten drunk.

Table 1 shows the prevalence of experimental use of alcohol by the adolescents according to different independent variables. Gender, skin color, and household assets index were not associated with experimental use of alcohol. Prevalence was higher in adolescents whose mothers reported drinking alcohol during pregnancy $(p=0.003)$. There was a direct association between experimental use of alcohol and parental alcohol consumption $(\mathrm{p}<0.001)$. Approximately one-third of the adolescents that reported family strife, running away from home, or working outside the home reported have tried alcohol $(p<0.001)$. School repetition was not statistically associated with the study outcome. More than
$60 \%$ of the adolescents that had used cigarettes or illicit drugs had already tried alcohol.

Table 2 shows prevalence ratios for experimental use of alcohol and the respective 95\% confidence intervals $(95 \% \mathrm{CI})$ in the crude and adjusted analyses. Gender, skin color, and household assets index were not associated with experimental use of alcohol, even after adjusting for confounding. Adolescents whose mothers had used alcohol during pregnancy showed a $60 \%$ greater risk of having tried alcohol. In relation to current parental alcohol use, when one parent drank, the risk of the adolescent having tried alcohol increased by $12 \%$; when both parents drank, the risk increased by $42 \%$. School repetition was initially not associated with the outcome, but after adjusting for confounding, it showed an inverse association with experimental use of alcohol, including lower risks in individuals that had repeated more than one grade. Having run away from home was not significantly associated with trying alcohol. The risk of having tried alcohol was 1.4 times greater among adolescents who reported working outside the home. Those that had tried smoking or illicit drugs showed 3.7 and 2.4 times the risk of having tried alcohol, respectively.

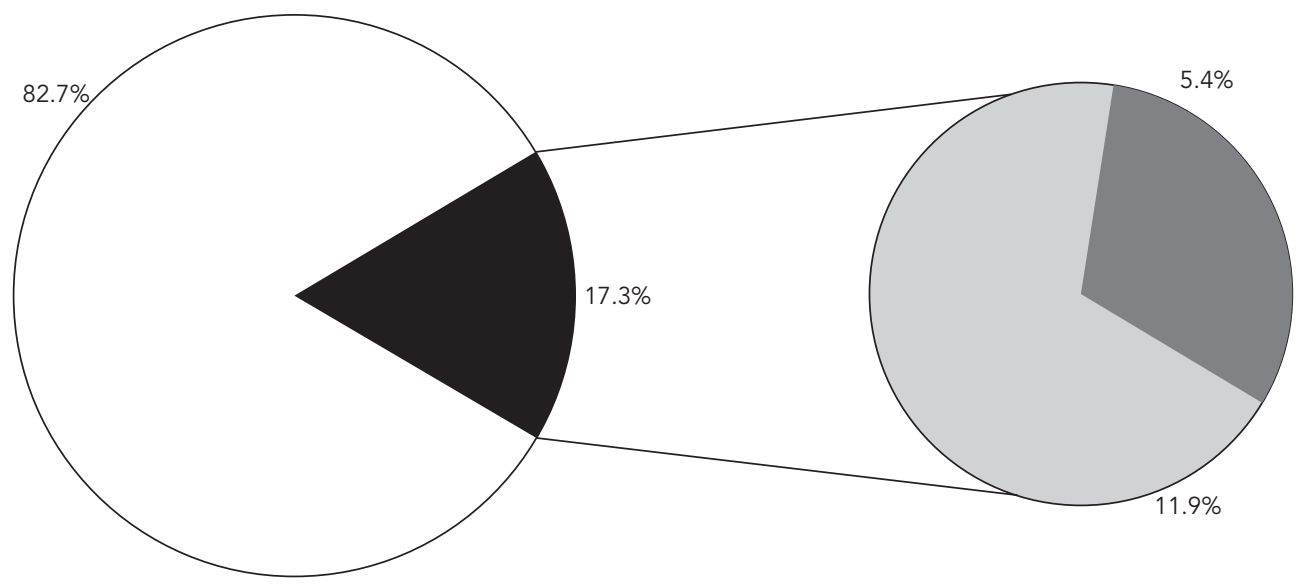

Experimental use of alcohol

Never

Already tried
Age at first use

10-11 years

9 years or younger 
Table 1

Prevalence of experimental use of alcohol at the 11 follow-up visit to the 1993 Pelotas (Brazil) birth cohort study.

\begin{tabular}{|c|c|c|c|}
\hline Variables & Prevalence & $95 \% \mathrm{Cl}$ & $\mathrm{p}$-value \\
\hline Gender * & & & 0.109 \\
\hline Female & 16.6 & $15.0-18.1$ & \\
\hline Male & 18.4 & $16.8-20.1$ & \\
\hline Skin color * & & & 0.738 \\
\hline White & 17.6 & $16.2-19.0$ & \\
\hline Black/Brown & 17.2 & $15.1-19.3$ & \\
\hline Household assets index (quintiles) ** & & & 0.353 \\
\hline 1st (lowest) & 16.7 & $14.1-19.2$ & \\
\hline $2^{\text {nd }}$ & 17.1 & $14.5-19.6$ & \\
\hline 3 rd & 18.8 & $16.2-21.5$ & \\
\hline $4^{\text {th }}$ & 16.7 & $14.2-19.2$ & \\
\hline $5^{\text {th }}$ (highest) & 18.8 & $16.2-21.5$ & \\
\hline Alcohol consumption in pregnancy * & & & 0.003 \\
\hline No & 17.1 & $15.9-18.2$ & \\
\hline Yes & 25.0 & $19.2-30.8$ & \\
\hline Parental alcohol consumption ** & & & $<0.001$ \\
\hline Neither parent & 14.1 & $11.8-16.5$ & \\
\hline One parent & 15.9 & $13.8-18.0$ & \\
\hline Both parents & 21.7 & $19.4-24.0$ & \\
\hline Family strife* & & & $<0.001$ \\
\hline Fights/Argues little & 16.8 & $15.6-18.0$ & \\
\hline Fights/Argues a lot & 32.1 & $26.4-37.7$ & \\
\hline School repetition ** & & & 0.261 \\
\hline Never repeated & 18.3 & $16.8-19.8$ & \\
\hline Repeated once & 13.8 & $11.6-16.0$ & \\
\hline Repeated more than once & 18.4 & $15.3-21.5$ & \\
\hline Ran away from home * & & & $<0.001$ \\
\hline No & 17.0 & $15.8-18.1$ & \\
\hline Yes & 32.2 & $24.5-39.9$ & \\
\hline Adolescent works outside of home * & & & $<0.001$ \\
\hline No & 17.0 & $15.8-18.1$ & \\
\hline Yes & 28.2 & $21.7-34.7$ & \\
\hline Tried smoking cigarettes * & & & $<0.001$ \\
\hline No & 15.5 & $14.4-16.6$ & \\
\hline Yes & 69.7 & $62.4-77.0$ & \\
\hline Tried other drugs * & & & $<0.001$ \\
\hline No & 17.3 & $16.1-18.4$ & \\
\hline Yes & 62.5 & $35.9-89.1$ & \\
\hline
\end{tabular}

95\% Cl: $95 \%$ confidence interval.

Note: the variable "parental alcohol consumption" showed the highest proportion of missing/unknown values (26.5\%). The other variables showed a maximum of $7.6 \%$ of missing/unknown values.

* Chi-square test for heterogeneity;

** Chi-square test for linear trend.

\section{Discussion}

A confidential, self-applied questionnaire is the most adequate and widely used method for studies on private or illicit behaviors 14,15 . The low rate of losses in this study is a positive characteristic suggesting the possibility of data extrapolation. This is one of the few studies in Brazil to have assessed the use of alcoholic beverages in early adolescence 16,17 . Although it is part of a longi- 
Table 2

Crude and adjusted analysis of the effects of independent variables on history of experimental use of alcohol recorded at the 11 follow-up visit to the 1993 Pelotas (Brazil) birth cohort study.

\begin{tabular}{|c|c|c|c|c|c|c|}
\hline \multirow[t]{2}{*}{ Variables } & \multicolumn{3}{|c|}{ Crude analysis } & \multicolumn{3}{|c|}{ Adjusted analysis * } \\
\hline & PR & $95 \% \mathrm{Cl}$ & p-value & PR & $95 \% \mathrm{Cl}$ & $\mathrm{p}$-value \\
\hline \multicolumn{7}{|l|}{ Gender ** } \\
\hline Female & 1.00 & & 0.109 & 1.00 & & 0.109 \\
\hline Male & 1.11 & $0.97-1.27$ & & 1.11 & $0.97-1.27$ & \\
\hline Skin color $\star \star$ & & & 0.841 & & & 0.995 \\
\hline White & 1.00 & & & 1.00 & & \\
\hline Black/Brown & 0.98 & $0.84-1.13$ & & 1.00 & $0.86-1.16$ & \\
\hline 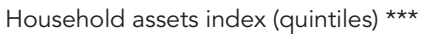 & & & 0.352 & & & 0.353 \\
\hline 1st (lowest) & 0.89 & $0.72-1.09$ & & 0.89 & $0.72-1.09$ & \\
\hline $2^{\text {nd }}$ & 0.91 & $0.74-1.12$ & & 0.91 & $0.74-1.12$ & \\
\hline 3 rd & 1.00 & $0.82-1.22$ & & 1.01 & $0.82-1.23$ & \\
\hline 4 th & 0.99 & $0.72-1.09$ & & 0.89 & $0.72-1.09$ & \\
\hline 5th (highest) & 1.00 & & & 1.00 & & \\
\hline Alcohol consumption in pregnancy ** & & & 0.002 & & & $<0.001$ \\
\hline No & 1.00 & & & 1.00 & & \\
\hline Yes & 1.47 & $1.15-1.86$ & & 1.60 & $1.23-2.07$ & \\
\hline Parental alcohol consumption *** & & & $<0.001$ & & & $<0.001$ \\
\hline Neither parent & 1.00 & & & 1.00 & & \\
\hline One parent & 1.13 & $0.91-1.39$ & & 1.12 & $0.90-1.39$ & \\
\hline Both parents & 1.54 & $1.27-1.87$ & & 1.42 & $1.16-1.73$ & \\
\hline Family strife ** & & & $<0.001$ & & & $<0.001$ \\
\hline Fights/Argues little & 1.00 & & & 1.00 & & \\
\hline Fights/Argues a lot & 1.91 & $1.58-2.30$ & & 1.55 & $1.23-1.95$ & \\
\hline 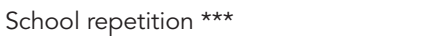 & & & 0.278 & & & 0.007 \\
\hline Never repeated & 1.00 & & & 1.00 & & \\
\hline Repeated once & 0.75 & $0.63-0.90$ & & 0.73 & $0.59-0.90$ & \\
\hline Repeated more than once & 1.00 & $0.83-1.21$ & & 0.80 & $0.63-1.01$ & \\
\hline Ran away from home ** & & & $<0.001$ & & & 0.309 \\
\hline No & 1.00 & & & 1.00 & & \\
\hline Yes & 1.90 & $1.48-2.42$ & & 1.20 & $0.85-1.68$ & \\
\hline Adolescent works outside of home ** & & & $<0.001$ & & & 0.015 \\
\hline No & 1.00 & & & 1.00 & & \\
\hline Yes & 1.66 & $1.31-2.11$ & & 1.41 & $1.07-1.87$ & \\
\hline Tried smoking cigarettes ** & & & & & & $<0.001$ \\
\hline No & 1.00 & & & 1.00 & & \\
\hline Yes & 4.51 & $3.98-5.11$ & & 3.75 & $3.11-4.53$ & \\
\hline Tried other drugs ** & & & $<0.001$ & & & $<0.001$ \\
\hline No & 1.00 & & & 1.00 & & \\
\hline Yes & 3.62 & $2.46-5.32$ & & 2.44 & $1.57-3.79$ & \\
\hline
\end{tabular}

95\% Cl: 95\% confidence interval; PR: prevalence ratio.

* Adjusted for gender, alcohol consumption during pregnancy, parental alcohol consumption, school repetition, teenage work, experimental cigarette smoking, and experimental use of other drugs

** Wald test for heterogeneity;

$\star \star \star$ Wald test for linear trend.

tudinal study, for some associations this article presents a cross-sectional analysis, thus involving limitations for establishing causal relations.
The prevalence of experimental use of alcohol in this cohort of adolescents was $17.5 \%$ (95\%CI: 16.3-18.6). A previous cross-sectional study with 
participation by 2,410 public and private school students ranging from 10 to 19 years of age showed an $86 \%$ overall prevalence of lifetime alcohol use 14 . From 10 to 12 years of age, the prevalence was $48 \%$, with no significant difference between boys and girls 14 . The need for peer acceptance or to display what are considered adult attitudes may explain part of the higher prevalence found in this study among schoolchildren, to the extent that the confidential questionnaire was completed by all the adolescents at the same time in a classroom. Meanwhile, in our household survey, the influence of parents or guardians, even though not direct, may have influenced the adolescents' answers, reducing the proportion of affirmative answers on drinking.

The mean age found by Vieira et al. 18 for first alcohol use was 12.4 years. In the 11-year age bracket, one-fourth of the adolescents (25.2\%) had already tried alcohol some time in life; as in our study, no significant difference was observed between boys and girls 18. Meanwhile, a study in Lithuania aimed at analyzing trends in the experimental use of alcohol among students 11, 13, and 15 years of age showed that boys tended to consume alcohol more regularly than girls. The same study also highlighted that experimental use of alcohol tended to increase with age 19 .

As in other studies, skin color was not associated with having tried alcohol 17. Likewise, the household assets index was not associated with the outcome. To evaluate the hypothesis that exposure to lower socioeconomic conditions in childhood could increase the risk of alcohol use by adolescents, the association was tested between family income at birth (measured in times the minimum wage) and experimental use of alcohol. Again, there was no association (linear $\mathrm{p}$-value trend $=0.148$ ). Wiles et al. ${ }^{20}$ published a systematic review of longitudinal populationbased studies on childhood socioeconomic status and risk of experimental use of alcohol later in life. The authors concluded that there is little evidence that childhood poverty is associated with alcohol use or abuse later in life.

Experimental use of alcohol in early adolescence was associated with alcohol consumption during pregnancy, alcohol consumption by both the parents, family strife, adolescents working outside the home, and experimental use of cigarettes and illicit drugs 21 . Parents (31\%) and friends (25\%) are the sources of access to alcoholic beverages that are cited most frequently by adolescents ${ }^{16}$. Parental drinking, combined with lack of parental concern and control over drinking by children and teens, is an important risk factor for lifetime alcohol abuse and addiction 22,23. The effects of family relations on experimental use of alcohol and other drugs are also well established $14,15,21,24$. Experimental use is more prevalent among adolescents with a history of family strife, permissiveness, and easy access. Interestingly, a history of running away from home was not associated with experimental use of alcohol. The small number of adolescents that reported having run away from home probably reduced the study's statistical power to assess this variable. In addition, the study only assessed adolescents that ran away but eventually returned home, possibly after making amends with close relatives; the adolescents that stayed away from home may have shown higher drinking rates.

Smoking and use of illicit drugs were significantly associated with alcohol use. Alcohol may be acting as a risk marker for the introduction of other drugs in this age bracket, to the extent that it is the drug used most frequently and prematurely in early adolescence. It is also known that experimental use of alcohol increases the tendency to join risky behavior groups 16 . According to Vieira et al. 18, the earlier the first use of alcoholic beverages, the earlier the first experience with smoking. Each year of delay in the introduction to alcohol use is associated with a 0.31 year delay in smoking $(\mathrm{p}<0.001)$. In the current study, the prevalence rates for smoking and illicit drug use among individuals that had already tried alcohol were $14.4 \%$ and $1.4 \%$, respectively. As compared to adolescents who had never tried alcohol, those who had already tried it showed a tenfold and eightfold risk of smoking and illicit drug use, respectively (PR = 10.9; 95\%CI: 7.8-15.2 and PR $=7.9$; 95\%CI: 2.9-21.6).

According to Brazil's 2001 National Household Sample Survey, or PNAD (Brazilian Institute of Geography and Statistics, IBGE), there were 5.4 million adolescents working in the country, one million of whom were not in school. Consistent with the literature 25 , we observed that teenage work increased the risk of alcohol use. According to a cross-sectional study in Cuiabá, Mato Grosso State, among public school students from 10 to 20 years of age, working teens showed higher rates of experimental use of alcohol than their non-working peers $(81 \%$ and $65 \%$, respectively; $\mathrm{p}<0.001) 17$. The same authors, studying the effect of teenage work on recent alcohol use, raised the following possible explanations for this association: contact with older people in the workplace, access facilitated by additional income acquired through work, work-related stress predisposing to use of psychoactive substances, decreased commitment to schoolwork, and premature transition to adult roles 26 .

A nationwide telephone survey was conducted in Australia in 2006 with parents and 
young people (12-25 years of age). Some $85 \%$ of the interviewees agreed that there were health risks associated with substances like alcohol, tobacco, and marijuana 7. Costa et al. 15, in a study on students 14-19 years of age, found that $86 \%$ of the adolescents considered themselves wellinformed on the risks associated with alcohol, cigarettes, and other psychoactive drugs. Despite the formal legal constraints, access to alcoholic beverages is relatively easy for Brazilian teens. More than half $(55 \%)$ of the adolescents consulted in a school survey reported that they had not experienced any difficulty in purchasing alcoholic beverages 16 .

The current study detected a high prevalence of experimental use of alcohol at 11 years of age. The most significant risk factors were family strife and parental example, as well as access to other drugs. Considering that experimental use of alcohol affects all social and age brackets, causing personal, family, and social harm, more effective measures should be taken to fight access to and use of alcohol, especially in early adolescence.

Although Brazil has waged an on-going campaign to combat alcohol, the issue is known to have been neglected by government authorities. The ban on liquor sales to minors in Brazil has been ineffective, and in practice children and young teens are able to purchase alcoholic beverages with the excuse that the liquor is for their parents. The lack of a serious policy and proper inspection with the enforcement of penalties for establishments that sell liquor to minors and for bars and other places where under-age individuals consume alcohol is responsible for the current high rate of alcohol use at 11 years of age.

\section{Resumo}

Este trabalho teve como objetivo avaliar a prevalência de uso experimental de bebidas alcoólicas e fatores associados no início da adolescência. Compuseram a amostra 4.452 adolescentes (média $=11,3$ anos; $D P=$ 0,3) da coorte de nascimentos de 1993 de Pelotas, Rio Grande do Sul, Brasil. O uso experimental de álcool foi referido por 17,5\% dos entrevistados (IC95\%: 16,318,6) e 5\% referiram ter experimentado com nove anos ou menos. O risco de uso experimental de álcool foi maior nos adolescentes cujas mães referiram ter bebido na gestação, quando ambos os pais usavam bebidas alcoólicas, entre os adolescentes que trabalhavam fora e naqueles que já experimentaram cigarro ou outras drogas. As relações familiares, o uso de álcool pelos pais, e o tabagismo do adolescente são os fatores for temente associados ao uso experimental de álcool no início da adolescência. Mais atenção deveria ser dada especialmente a esses grupos, a fim de combater o consumo precoce de álcool.

Bebidas Alcoólicas; Adolescente; Estudos de Coorte

\section{Contributors}

R. B. Noal participated in the data analysis and writing of the article. A. M. B. Menezes and C. L. Araújo collaborated in coordinating the research and preparing and writing the article. P. C. Hallal contributed with the coordination of the research, data analysis, and writing of the article.

\section{Acknowledgments}

The cohort study is supported by the Wellcome Trust. The initial phases of the cohort were funded by the European Union and the Brazilian National Program for Centers of Excellence (PRONEX), National Research Council (CNPq), and Ministry of Health. 


\section{References}

1. World Health Organization. Global status report: alcohol and young people. Geneva: World Health Organization; 2001.

2. World Health Organization. Global status report on alcohol 2004. Geneva: World Health Organization; 2004.

3. Jamison DT, Breman JG, Measham AR, Alleyne G, Claeson M, Evans DB, et al. Disease control priorities in developing countries. 2nd Ed. Washington DC: World Bank/New York: Oxford University Press; 2006.

4. Clark S. Youth access to alcohol: early findings from a community action project to reduce the supply of alcohol to teens. Subst Use Misuse 2007; 42:2053-62.

5. Rehm J, Sempos CT, Trevisan M. Alcohol and cardiovascular disease: more than one paradox to consider. Average volume of alcohol consumption, patterns of drinking and risk of coronary heart disease: a review. J Cardiovasc Risk 2003; 10:15-20.

6. Andersen A, Due P, Holstein BE, Iversen L. Tracking drinking behaviour from age 15-19 years. Addiction 2003; 98:1505-11.

7. Galduroz JC, Noto AR, Nappo SA, Carlini EA. Trends in drug use among students in Brazil: analysis of four surveys in 1987, 1989, 1993 and 1997. Braz J Med Biol Res 2004; 37:523-31.

8. Fergusson DM, Lynskey MT, Horwood LJ. Childhood exposure to alcohol and adolescent drinking patterns. Addiction 1994; 89:1007-16.

9. Galduroz JC, Carlini EA. Use of alcohol among the inhabitants of the 107 largest cities in Brazil, 2001. Braz J Med Biol Res 2007; 40:367-75.

10. Araújo CL, Menezes AMB, Vieira MFA, Neutzling MB, Gonçalves H, Anselmi L, et al. The 11-year follow-up of the 1993 Pelotas (Brazil) birth cohort study: methods. Cad Saúde Pública 2010; 26 : 1875-86.

11. Victora CG, Huttly SR, Fuchs SC, Olinto MT. The role of conceptual frameworks in epidemiological analysis: a hierarchical approach. Int J Epidemiol 1997; 26:224-7.

12. Barros AJ, Hirakata VN. Alternatives for logistic regression in cross-sectional studies: an empirical comparison of models that directly estimate the prevalence ratio. BMC Med Res Methodol 2003; $3: 21$.

13. Victora CG, Araújo CLP, Menezes AMB, Hallal PC, Vieira MF, Neutzling MB, et al. Methodological aspects of the 1993 Pelotas (Brazil) birth cohort study. Rev Saúde Pública 2006; 40:39-46.

14. Tavares BF, Béria JU, Lima MS. Prevalência do uso de drogas e desempenho escolar entre adolescentes. Rev Saúde Pública 2001; 35:150-8.
15. Costa MCO, Alves MVQM, Santos CAST, Carvalho RC, Souza KEP, Sousa HL. Experimentação e uso regular de bebidas alcoólicas, cigarros e outras substâncias psicoativas (SPA) na adolescência. Ciênc Saúde Coletiva 2007; 12:1143-54.

16. Vieira DL, Ribeiro M, Romano M, Laranjeira RR. Álcool e adolescentes: estudo para implementar políticas municipais. Rev Saúde Pública 2007; 41:396-403.

17. Souza DP, Areco KN, Silveira Filho DX. Álcool e alcoolismo entre adolescentes da rede estadual de ensino de Cuiabá, Mato Grosso. Rev Saúde Pública 2005; 39:585-92.

18. Vieira DL, Ribeiro M, Laranjeira R. Evidence of association between early alcohol use and risk of later problems. Rev Bras Psiquiatr 2007; 29:222-7.

19. Zaborskis A, Sumskas L, Maser M, Pudule I. Trends in drinking habits among adolescents in the Baltic countries over the period of transition: HBSC survey results, 1993-2002. BMC Public Health 2006; 6:67.

20. Wiles NJ, Lingford-Hughes A, Daniel J, Hickman M, Farrell M, Macleod J, et al. Socio-economic status in childhood and later alcohol use: a systematic review. Addiction 2007; 102:1546-63.

21. Baus J, Kupek E, Pires M. Prevalência e fatores de risco relacionados ao uso de drogas entre escolares. Rev Saúde Pública 2002; 36:40-6.

22. Grunbaum JA, Kann L, Kinchen S, Ross J, Hawkins J, Lowry R, et al. Youth risk behavior surveillance: United States, 2003. MMWR Surveill Summ 2004; 53:1-96.

23. Kuntsche E, Rehm J, Gmel G. Characteristics of binge drinkers in Europe. Soc Sci Med 2004 59:113-27.

24. Menezes AMB, Hallal PC, Horta BL. Early determinants of smoking in adolescence: a prospective birth cohort study. Cad Saúde Pública 2007; 23:347-54.

25. Valois RF, Dunham AC, Jackson KL, Waller J. Association between employment and substance abuse behaviors among public high school adolescents. J Adolesc Health 1999; 25:256-63.

26. Souza DPO, Silveira Filho DX. Uso recente de álcool, tabaco e outras drogas entre estudantes adolescentes trabalhadores e não trabalhadores. Rev Bras Epidemiol 2007; 10:276-87.

27. Lubman DI, Hides L, Jorm AF. Beliefs of young people and their parents about the harmfulness of alcohol, cannabis and tobacco for mental disorders. Med J Aust 2007; 187:266-9.

Submitted on $02 / \mathrm{Feb} / 2009$

Final version resubmitted on 01/Apr/2010

Approved on 16/Apr/2010 